\title{
The role of hormones on Toxoplasma gondii infection: a systematic review
}

\section{María de la Luz Galván-Ramírez *, Adrián Fernando Gutiérrez-Maldonado, Fabiola Verduzco-Grijalva and Judith Marcela Dueñas Jiménez}

Neurophysiology Laboratory, Department of Physiology, Health Sciences University Center, University of Guadalajara, Guadalajara, Jalisco, Mexico

\section{Edited by:}

Veeranoot Nissapatorn, University of

Malaya, Malaysia

Reviewed by:

Xun Suo, China Agricultural

University, China

Jorge Enrique Gómez Marín,

Universidad del Quindio, Colombia

Jaroslav Flegr, Charles University,

Czech Republic

*Correspondence:

María de la Luz Galván-Ramírez,

Centro Universitario de Ciencias de

la Salud, Universidad de

Guadalajara, Sierra Mojada \# 950,

Colonia Independencia, Guadalajara,

Jalisco, CP 44340, México

e-mail:mlgalvanr@gmail.com
Background: Toxoplasma gondii is the causal agent of toxoplasmosis in which one third of the world's population has been infected. In pregnant women, it may cause abortion and severe damage to the fetal central nervous system. During pregnancy, the prevalence of toxoplasmosis increases throughout the second and third quarter of gestation, simultaneously progesterone and $17 \beta$-estradiol also increase. Thus, it has been suggested that these hormones can aggravate or reduce parasite reproduction. The aim of this study was reviewing the relationship between hormones and infection caused by $T$. gondii in several experimental animal models and humans, focused mainly on: (a) congenital transmission, (b) parasite reproduction, (c) strain virulence, (d) levels of hormone in host induced by $T$. gondii infection, and (e) participation of hormone receptors in $T$. gondii infection. Are the hormones specific modulators of T. gondii infection? A systematic review methodology was used to consult several databases (Pub Med, Lilacs, Medline, Science direct, Scielo, Ebsco, Sprinker, Wiley, and Google Scholar) dated from September, 2013 to March, 2014.

Results: Thirty studies were included; eight studies in humans and 22 in animals and cell cultures. In the human studies, the most studied hormones were testosterone, progesterone, prolactin, and 17 $\beta$-estradiol. Type I (RH and BK) and Type II (Prugniaud, SC, ME49, T45, P78, and T38) were the most frequent experimental strains.

Conclusions: Thirty-five years have passed since the first studies regarding T. gondii infection and its relationship with hormones. This systematic review suggests that hormones modulate T. gondii infection in different animal models. However, given that data were not comparable, further studies are required to determine the mechanism of hormone action in the $T$. gondii infectious process.

Keywords: Toxoplasma infection, steroids hormones, no steroid hormones, toxoplasmosis, Toxoplasma

\section{INTRODUCTION}

Toxoplasma gondii (T. gondii) is the causal agent of toxoplasmosis and one third of the world population has been affected by this parasite (el-On and Peiser, 2003). In immunocompetent adults, $80 \%$ of the cases can be asymptomatic. On the other hand, in immunocompromised patients, T. gondii is an opportunistic parasite that has been held responsible for mortal encephalitis (Cabrera-Muñoz et al., 2010).

Congenital transmission of $T$. gondii causes severe consequences in which the degree of damage depends on the time when the mother is infected (Speroff et al., 1999). Infection during early pregnancy can result in apoptosis of placental cells and fetal resorption (Senegas et al., 2009). When pregnant females infected during latter stage of pregnancy and inflammatory responses are low, congenital transmission is likely to occur (Roberts et al., 2001; Pfaff et al., 2008). The transmission frequency of T. gondii is high $(80 \%)$ at end of pregnancy.

\section{PREGNANCY AND $T$. gondii INFECTION}

During pregnancy, maternal hormones alter the immune responses of the mother in the presence of fetal antigens. The increases in the susceptibility to infection and a diminished proinflammatory response have critical anti-parasitic properties that cause an unfavorable development of toxoplasmosis (Craig et al., 2001; Roberts et al., 2001; Prigione et al., 2006; Dionne et al., 2012). In the second and third trimester of gestation, there is a significant increase of $17 \beta$-estradiol and progesterone levels and it is during this period, when the prevalence of Toxoplasma infection increases (Montoya and Remington, 2008; Al-warid and Al-qadhi, 2012).

\section{7 $\beta$-ESTRADIOL AND $T$. gondii INFECTION}

$17 \beta$-estradiol (E2) is synthetized mainly in the ovary, breast, endometrial tissue, and brain. E2 plays a vital role in the menstrual cycle and human reproduction. In the nervous system, the estrogens are neuroprotective (Duenas et al., 1996; Arevalo 
et al., 2010). It has been reported that the administration of pharmacological doses of $17 \beta$-estradiol increases the susceptibility to Toxoplasma infection (Pung and Luster, 1986).

\section{PROGESTERONE}

Progesterone is present in the ovary and corpus luteum where it is primarily involved in the second phase of the menstrual cycle and reproductive processes of women. Progesterone is synthetized in breast, endometrial, and brain too (Speroff et al., 1999). In cells infected with tachyzoites of $T$. gondii, progesterone did not regulate the replication of parasites (Gay-Andrieu et al., 2002). Progesterone levels are reduced during pregnancy in sheep after infection by T. gondii (Aiumalamai et al., 1990; Fredriksson et al., 1990).

\section{TESTOSTERONE LEVELS REGULATION BY T. gondii INFECTION IN HUMAN BEINGS AND MICE}

Testosterone and their derivatives (dihydrotestosterone and dehydroepiandrosterone) are androgens produced mainly in male gonads, adrenal glands and the brain. Testosterone can act directly as a ligand of androgen receptors (AR) found in several target tissues. Androgens stimulate the development of the secondary sexual characters in males, participate in human reproduction and maturation of human fetal testes (O'Shaughnessy and Fowler, 2014). In the brain, it is considered as a neuroprotective hormone (Kurth et al., 2014). IgG anti-Toxoplasma antibodies were significantly correlated to testosterone (Shirbazou et al., 2011), and results are different accord type strain (Kaňková et al., 2011). T. gondii produces high testosterone levels in infected animals and mRNA expression of luteinizing hormone receptor (LHR) (Oktenli et al., 2004; Abdoli et al., 2012; Lim et al., 2013).

\section{THYROXINE (T4) AND T. gondii INFECTION}

Studies in Nylar female mice infected with T. gondii, exhibited hypogonadotrophic hypogonadism secondary to hypothalamic dysfunction (Stahl et al., 1985, 1994). These mice infected with T. gondii Cornell strain, present atrophy in the thymus, ovaries, and uterus, cessation of cycling, anovulation, and decline of serum thyroxine (T4) levels (Stahl et al., 1985).

\section{CORTICOSTEROIDS EFFECT ON T. gondii}

Cortisol is a glucocorticoid hormone secreted by the adrenal cortex. It works through a signal transduction pathway that initiates by hormone linkage to specific cell receptors. Proteins synthesized by the glucocorticoid response inhibit or stimulate the specific tissue (Gardner et al., 2011). Cortisone increased the amount of tachyzoites, cysts and cystozoite, as the breakage of cysts released a higher resistant antigen-cystozoite in mice brains infected with T. gondii (Hulínská et al., 1990).

\section{ANTI-PARASITIC EFFECT OF PROLACTIN ON $T$. gondii INFECTION}

PRL is capable of inhibiting multiplication of Toxoplasma in murine microglial cell cultures (Benedetto et al., 2001). PRL significantly restricted intracellular growth of Toxoplasma in mice and human cell lines (Dzitko et al., 2010, 2012). Moreover, it been documented that women with hyperprolactinemia showed lower T. gondii prevalence (Dzitko et al., 2008). It has been reported that serum human prolactin (shPRL) has the capacity to bind to live RH tachyzoites (type I) and ME49 (type II) strains in a specific way (Dzitko et al., 2013).

The aim of this study was to review the relationship between hormones and infection by $T$. gondii in several experimental animal models and humans. Focusing the information on: (a) congenital transmission, (b) parasite reproduction, (c) strain virulence, (d) levels of hormone in host induced by T. gondii infection, (e) participation of hormone receptors in T. gondii infection.

\section{MATERIALS AND METHODS DATABASE SEARCH}

Reports from September 2013 to February 2014 were obtained from a total of nine databases (Pub Med, Lilacs, Medline, Science direct, Scielo, Ebsco, Sprinker, Wiley, Google Scholar). Mesh terms were "Toxoplasma or toxoplasmosis or Toxoplasma gondii" combined with progesterone, 17 $\beta$-estradiol, testosterone, cortisol, cortisone, aldosterone, 11-desoxicorticosterone, dihydrotestosterone, dehydroepiandrosterone, and non-steroid hormones; growth hormone, prolactin, parathyroid hormone, corticotrophin, insulin, glucagon, luteinizing hormone, thyroid stimulating hormone, human chorionic gonadotropin, antidiuretic hormone, oxytocin, melanocyte stimulating hormone, somatostatin, thyrotropin-releasing hormone, gonadotropinreleasing hormone, noradrenaline, adrenaline, melatonin, thyroxine, and triiodothyronine. Toxoplasma and hormones and strain Toxoplasma. The criteria used for including data were: the full text of papers written in English (reviews and case reports not considered), studies performed on humans, animals, and in cell cultures.

\section{DATA COLLECTION METHODS}

Two reviewers (GRML and GMAF) carefully studied all selected studies. The full text of selected original articles were obtained and reviewed. Inclusion criteria for this analysis were explicit data of all independent variables and at least one dependent variable; data collection and criteria eligibility were established for determining the frequency or proportion of each study. The independent variables were $T$. gondii strain, hormones, study design, stage of infection and developmental stage of the parasite, post infection evaluation time, age, host, and technical analysis. Dependent variables were increased or decreased of infection and number of parasites. Reference lists of full-text publications were examined for identifying studies not originally selected Figure 1.

From 30 articles meeting inclusion criteria, all results were captured on an Excel database. A number of studies presented frequency distribution of dependent variables; in these cases, the sum of the products of each value by frequency was included for comparison in the database. Some articles presented ranges, mean plus standard deviation; these articles were included in the database using the median.

\section{RESULTS}

One thousand two hundred and seventy eight articles potentially related to T. gondii or hormones were found. However, only 45 were selected and of these, 30 met the inclusion criteria for this 
Databases: Pub Med, Lilacs, Medline, Science direct, Scielo, Ebsco, Sprinker, Wiley, Google Scholar.

Keywords: Toxoplasma, toxoplasmosis or Toxoplasma gondii in combined with $17 \beta$-estradiol, testosterone, cortisol, cortisone, aldosterone, 11-desoxicorticosterone, dihydrotestosterone, dehydroepiandrosterone. Non-steroids hormones; growth hormone, prolactin, parathyroid, corticotrophin, insulin, glucagon, Luteinizing, thyroid stimulating, human chorionic gonadotropin, antidiuretic hormone, oxytocin, melanocyte stimulating, somatostatin, thyrotropin-releasing, gonadotropin-releasing, noradrenaline, adrenaline, melatonin, thyroxine and triiodothyronine.

$\mathbf{1 2 7 8}$ potentially relevant literatures were identified

Reading literature case reports, reviews and articles not to talk about hormones and Toxoplasma or toxoplasmosis were removed (1233)

45 articles were selected to be probably included in the review

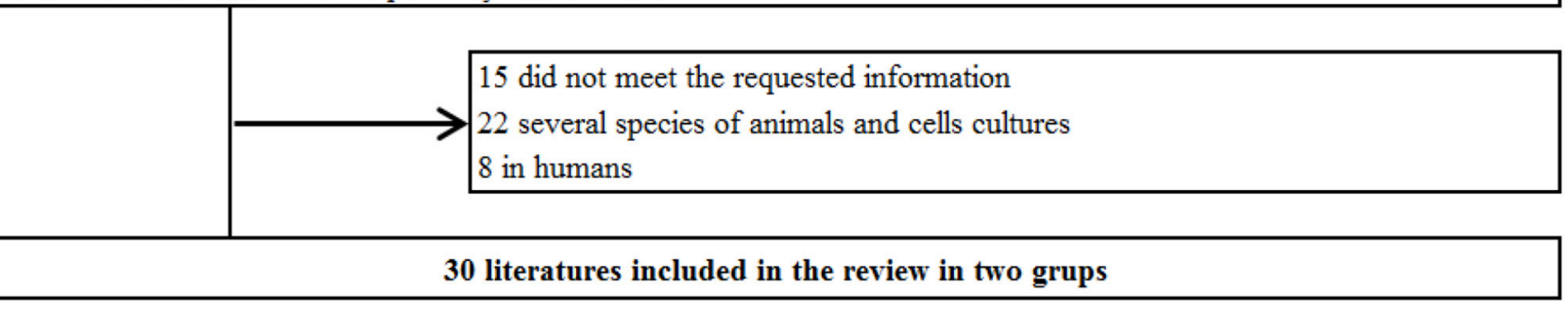

FIGURE 1 | This figure shows the flow of the search obtained, data collection methods, and database search.

systematic review. The analysis was divided into three categories: (A) humans in Table 1, (B) several species of animals in Table 2, and (C) Cell cultures in Table 3 and studies conducted in the time period that this research included Figure 2.

\section{HUMANS}

Eight articles were performed with different hormones on humans, from 17 to 40 years old: Testosterone $(n=5)$ (Oktenli et al., 2004; Hodková et al., 2007; Flegr et al., 2008a,b; Shirbazou et al., 2011), 17 $\beta$-estradiol and progesterone, dehydroepiandrosterone (DHEA), prolactin, and cortisol and testosterone $(n=1)$ (Dzitko et al., 2008; Al-warid and Al-qadhi, 2012; de la Torre et al., 2012). These studies used Radioimmunoassay (RIA) or Enzymelinked ImmunoSorbent assay (ELISA) in 8 studies combined with other analytic methods (Table $\mathbf{1}$ ).

\section{ANIMALS}

Fifteen articles evaluated the hormone effect in T. gondii infection using different animal models: murine model $(n=12)$; in guinea-pigs (1) (Kittas and Henry, 1979), in mice (8) (Kittas and Henry, 1980; Pung and Luster, 1986; Hulínská et al., 1990; Stahl and Kaneda, 1998a,b; Liesenfeld et al., 2001; Kaňková et al., 2011; Puvanesuaran et al., 2012), and rats (3) (Abdoli et al., 2012; Lim et al., 2013; Mitra et al., 2013). Two from ewes (2) (Aiumalamai et al., 1990; Fredriksson et al., 1990) and one for goats (1) (Engeland et al., 1996) (Table 2).

Progesterone and testosterone were the most studied hormones $(n=4)$, estradiol $(n=3)$, corticosterone and thyroxine $(n=2)$ and cortisone, adrenaline, and prednisolone $(n=1)$.
Eight T. gondii strains were also analyzed: two Type I (eight RH and four BK) and six Type II (two PRU, ME49 and SC and one T45, P78, T38) and two not specified (Table 2).

The most frequent parasite stage of development studied was the tachyzoite $(n=11)$, followed by cyst $(n=8)$, ooquiste $(n=$ 2 ), and bradizoite $(n=1)$. The number of parasites used for each experiment depended on the stage of parasite development and the host. In the murine model, tachyzoites from $1 \times 10^{4}$ to $1 \times 10^{7}$ were used (Benedetto et al., 2001; Abdoli et al., 2012; Dzitko et al., 2013). The number of cysts used in different rodent species was from 8 to 100 (Stahl and Kaneda, 1998b; Liesenfeld et al., 2001). In an experiment with goats, 1250 bradyzoytes were used (Engeland et al., 1996) and in another study with sheep infected with ooquistes, the number of ooquistes was not indicated (Aiumalamai et al., 1990) (Table 2).

The post-infection time in each experiment was different, according to each species and parasite stage of development. In guinea pigs, 42 days (Kittas and Henry, 1979); mice, 4 to 60 days (Kittas and Henry, 1980; Pung and Luster, 1986; Hulínská et al., 1990; Stahl and Kaneda, 1998a,b; Liesenfeld et al., 2001; Kaňková et al., 2011; Puvanesuaran et al., 2012); in rats, 10 to 56 days (Abdoli et al., 2012; Lim et al., 2013; Mitra et al., 2013), in a goat, 54 to 73 days (Engeland et al., 1996) and in ewes 90.5 days (Aiumalamai et al., 1990; Fredriksson et al., 1990) (Table 2).

Concerning the route of infection, 15 studies were carried out, four subcutaneous (Kittas and Henry, 1979, 1980; Pung and Luster, 1986; Engeland et al., 1996) and six more by peritoneal administration (Hulínská et al., 1990; Stahl and Kaneda, 1998a,b; Abdoli et al., 2012; Lim et al., 2013; Mitra et al., 


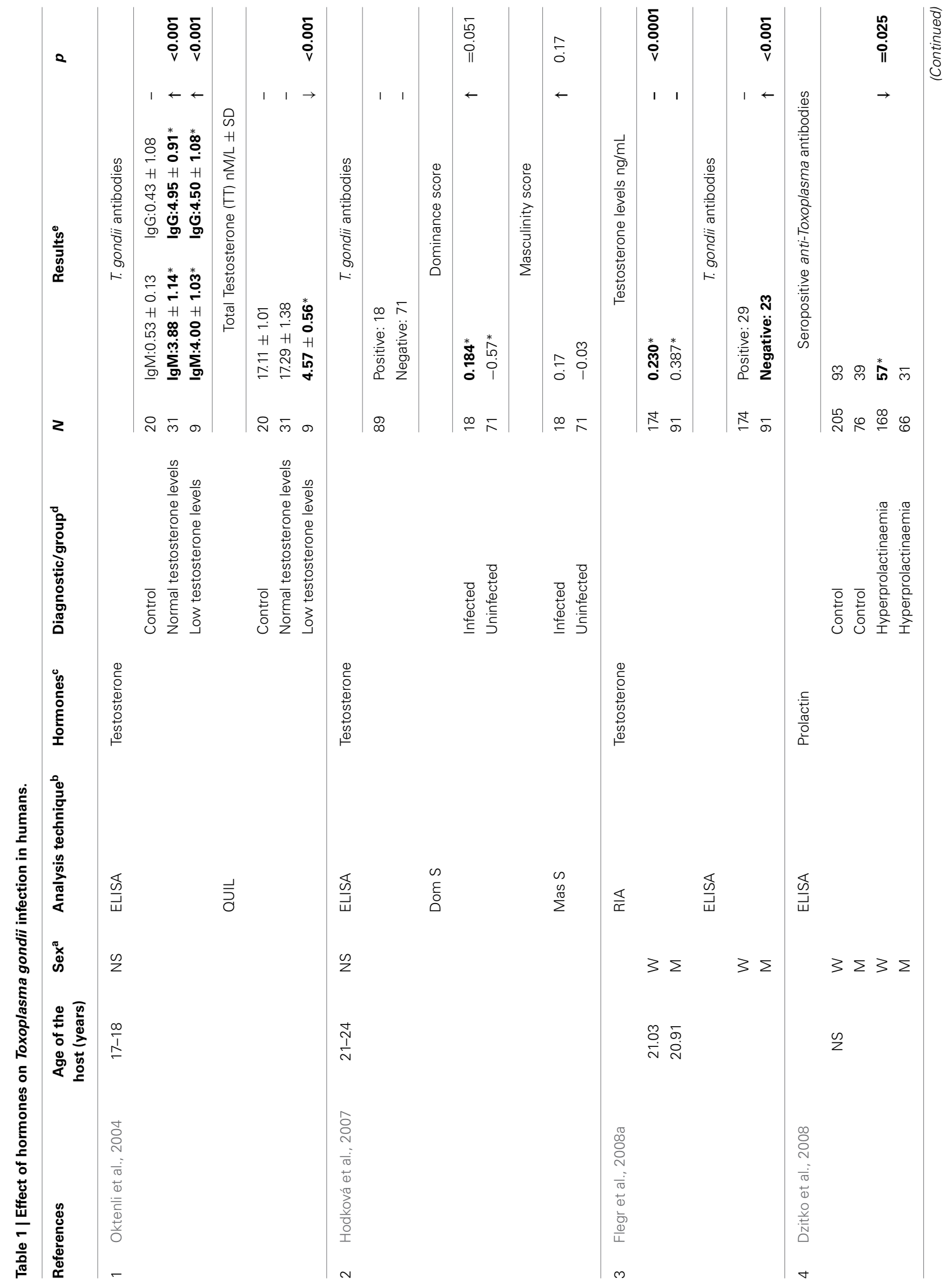




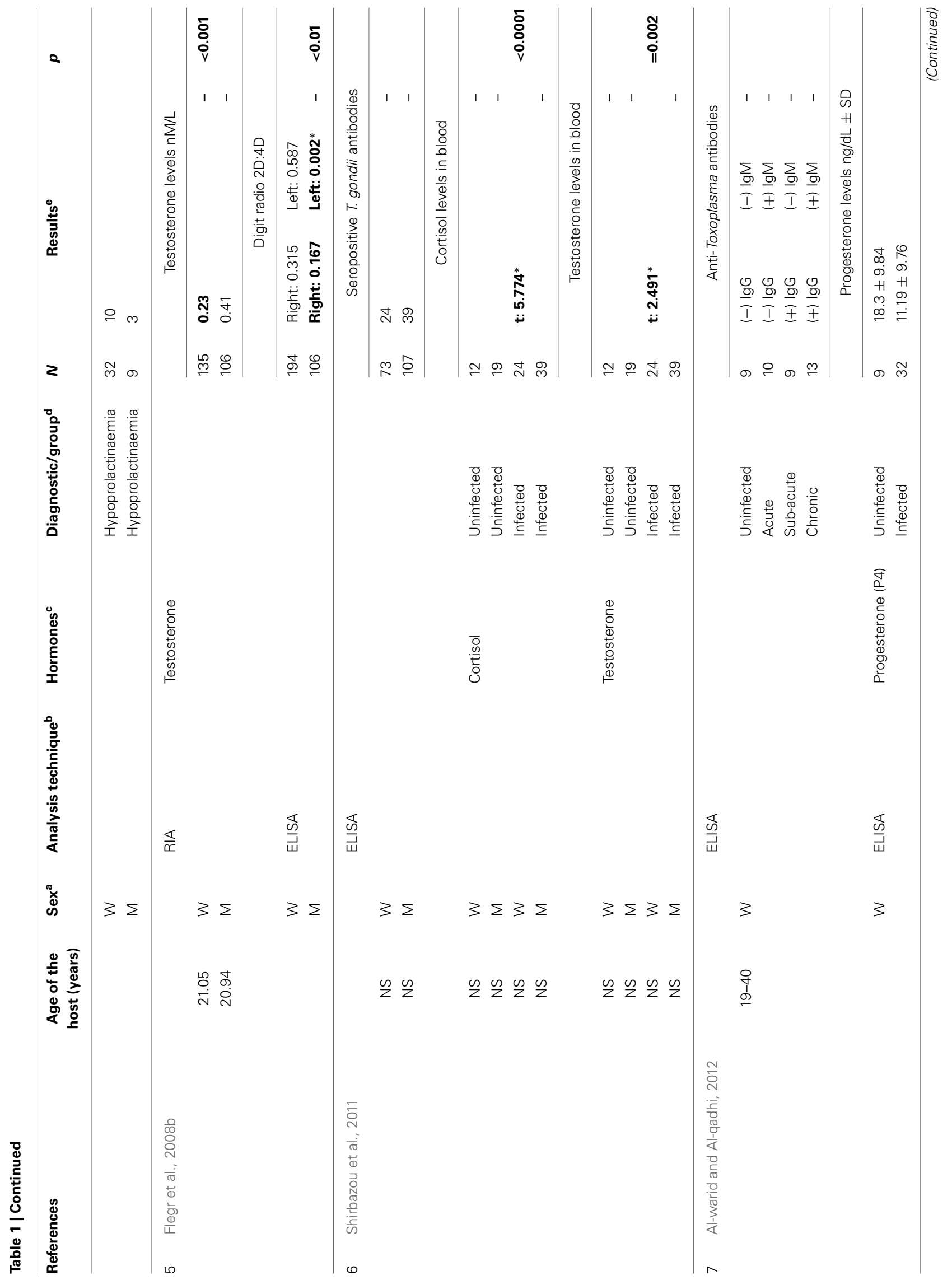




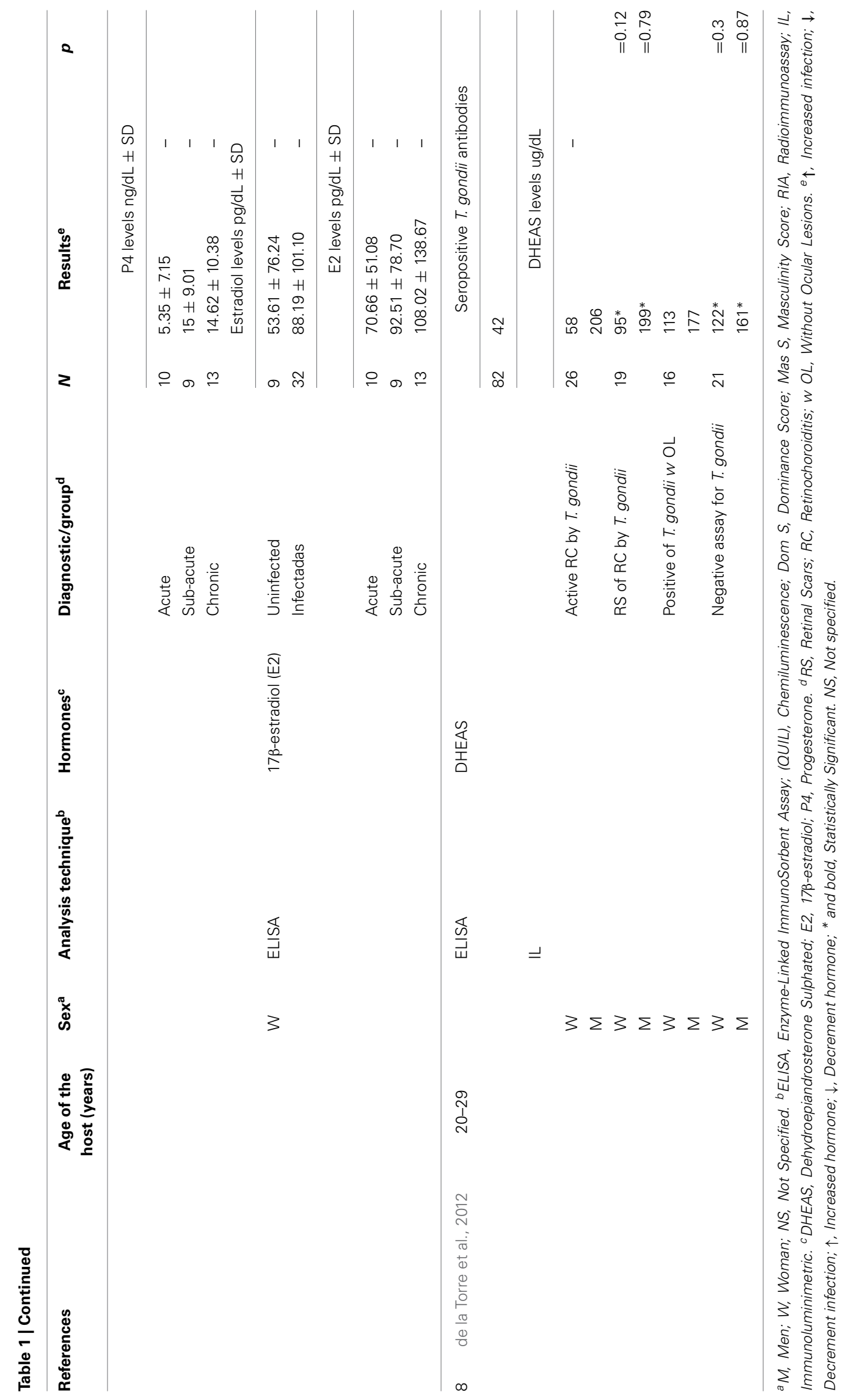




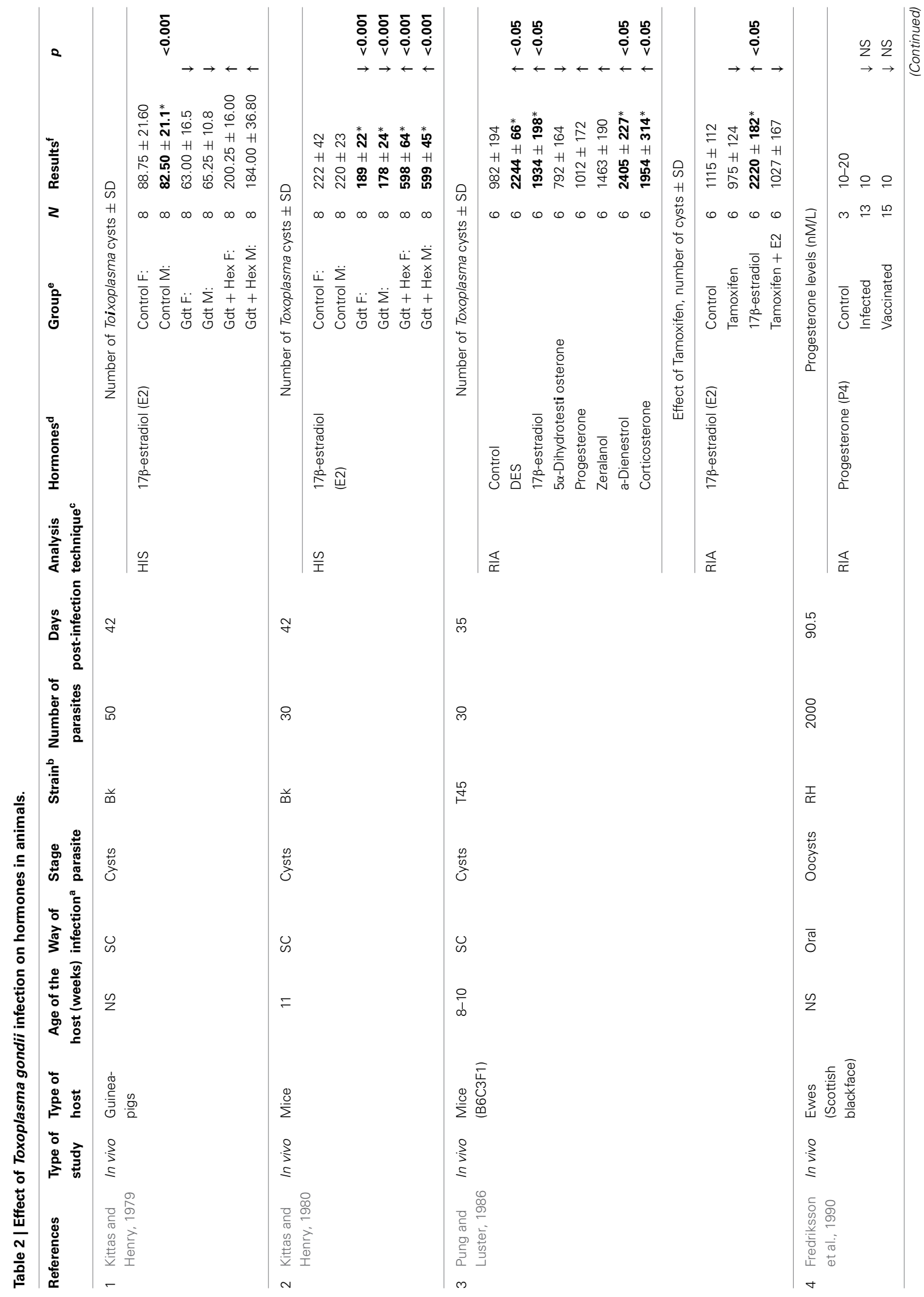









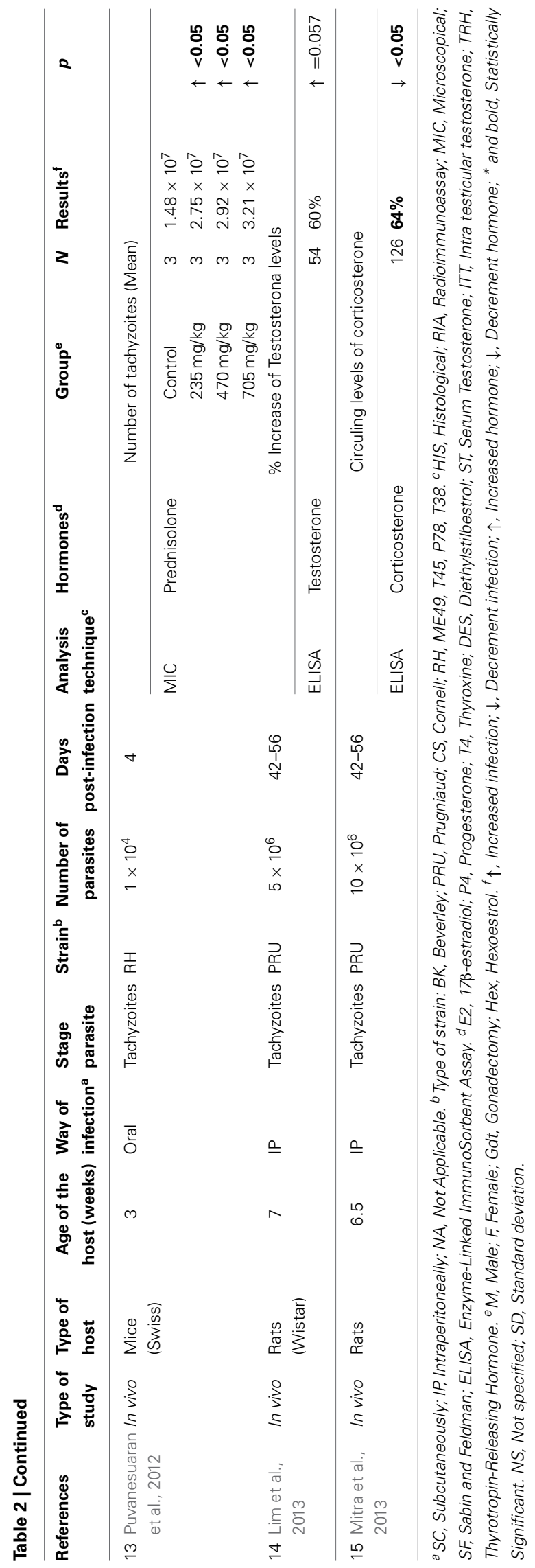

2013). In four studies, oral administration was used for infection (Fredriksson et al., 1990; Liesenfeld et al., 2001; Kaňková et al., 2011; Puvanesuaran et al., 2012) and one was not specified (Aiumalamai et al., 1990) (Table 2).

\section{CELL CULTURES}

Seven studies were designed in cell lines; two in RAW 264.7 mouse cell lines (Gay-Andrieu et al., 2002; Gets and Monroy, 2005), one, in bone marrow stem cells (Jones et al., 2008) one in microglial cell cultures (Benedetto et al., 2001) and three with prolactin in Murine L929, Human Hs27, HeLa, and Peritoneal Blood Mononuclear cells (PBMC) (Dzitko et al., 2010, 2012, 2013; Abdoli et al., 2012) (Table 3).

Concerning non-steroid hormones, prolactin and thyroxine hormone have been studied. In this study, other non-steroid hormones such as growth hormone, parathyroid, corticotrophin, insulin and glucagon, luteinizing and follicle hormone, thyroid stimulating, human chorionic gonadotropin, antidiuretic, oxytocin, melanocyte stimulating, somatostatin, thyrotropinreleasing hormone, gonadotropin-releasing hormone, noradrenaline, adrenaline, melatonin, and triiodothyronine were not associated to Toxoplasma infection.

The laboratory analysis methods used were: Radioimmunoassay (RIA) (Pung and Luster, 1986; Aiumalamai et al., 1990; Kaňková et al., 2011). EnzymeLinked Immunosorbent Assay (ELISA) (Engeland et al., 1996; Abdoli et al., 2012; Dzitko et al., 2012, 2013; Lim et al., 2013). A Morphological Method, (MM), Indirect Immunofluorescence (IFI), Flow Cytometry Analysis (CF) (Gay-Andrieu et al., 2002), Microscopy (Hulínská et al., 1990; Gay-Andrieu et al., 2002), in three histological studies (Kittas and Henry, 1979, 1980; Hulínská et al., 1990) and in two methods. Sabin and Feldman (SF) (Engeland et al., 1996) Inverse Reaction of Polymerase Chain and ELISA (Lim et al., 2013).

\section{DISCUSSION}

Congenital toxoplasmosis is one of the most significant burdens of T. gondii infection in humans. Both the maternal-fetal transmission and hormonal levels during pregnancy are poorly understood and yet, may play an important role during the course of the disease. In pregnant women with acute toxoplasmosis, low levels of progesterone and low levels of estrogens can induce severe infection caused by $T$. gondii (Al-warid and Al-qadhi, 2012). The changes in endocrine phenomena occurring during pregnancy, as well as the size and maturity of the placenta and the embryonic/fetal immune response definitely affect the ability to be protected from invasion or to fight infection (Ortiz-Alegría et al., 2010).

In pregnant women with toxoplasmosis, low levels of progesterone and estrogen can induce severe infection. Nevertheless, the mechanism is unknown (Al-warid and Al-qadhi, 2012). Current studies show that there weren't any statistically significant differences in progesterone levels between infected and uninfected women with $T$. gondii, although higher progesterone levels were observed in uninfected women compared to low level in infected women. Moreover, estrogen levels in both chronic and uninfected women did not exhibit significant differences, although 


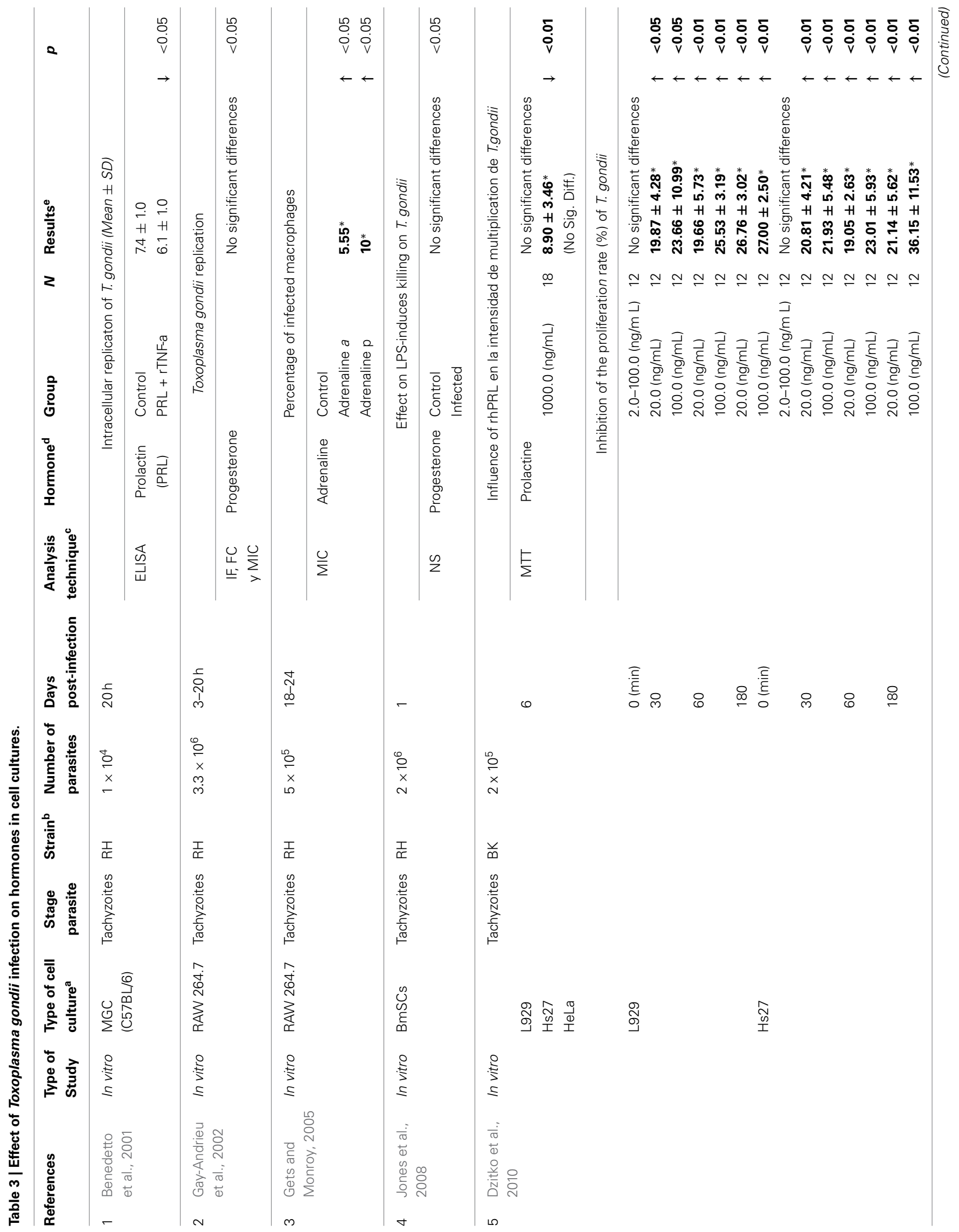




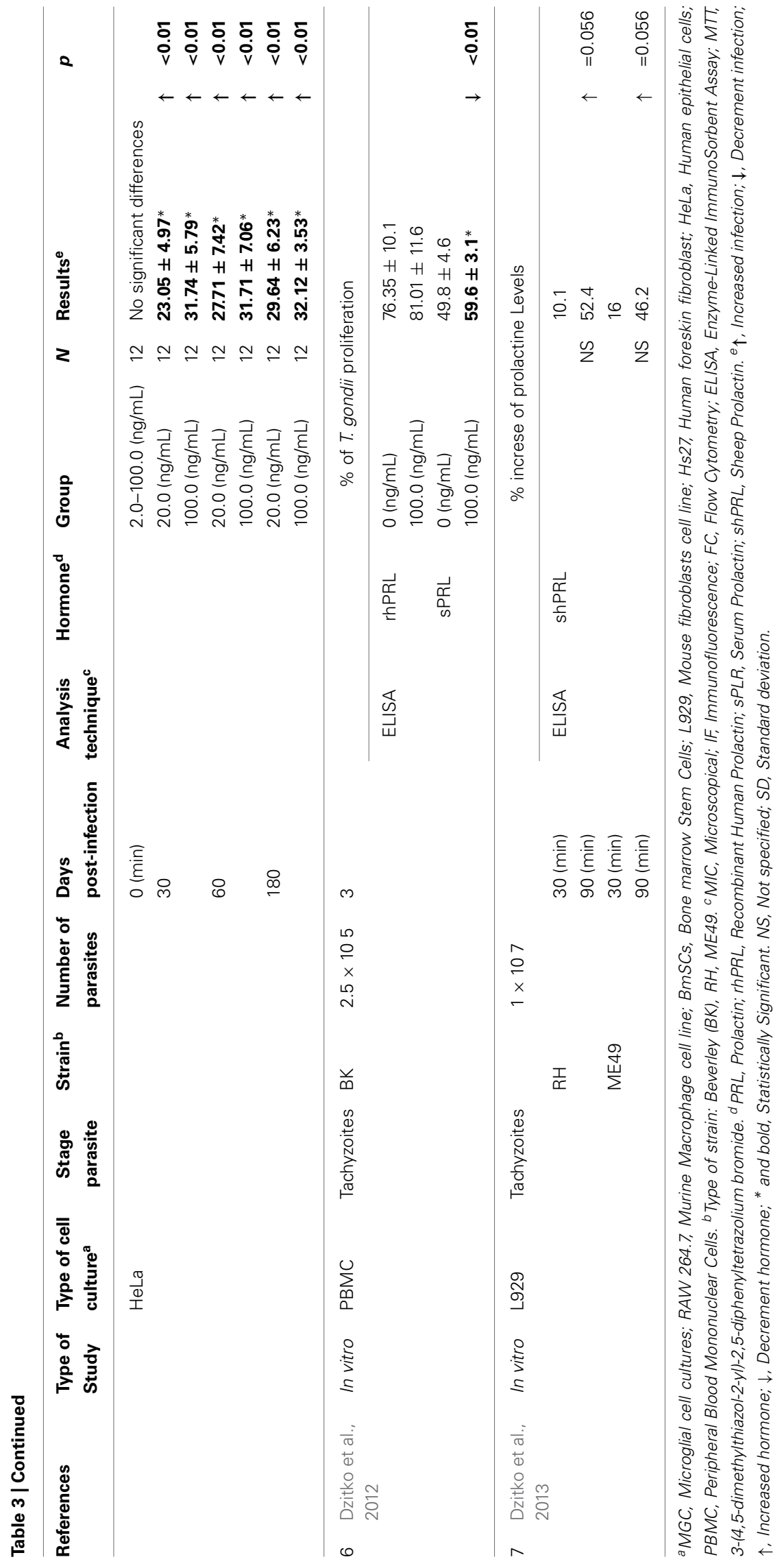




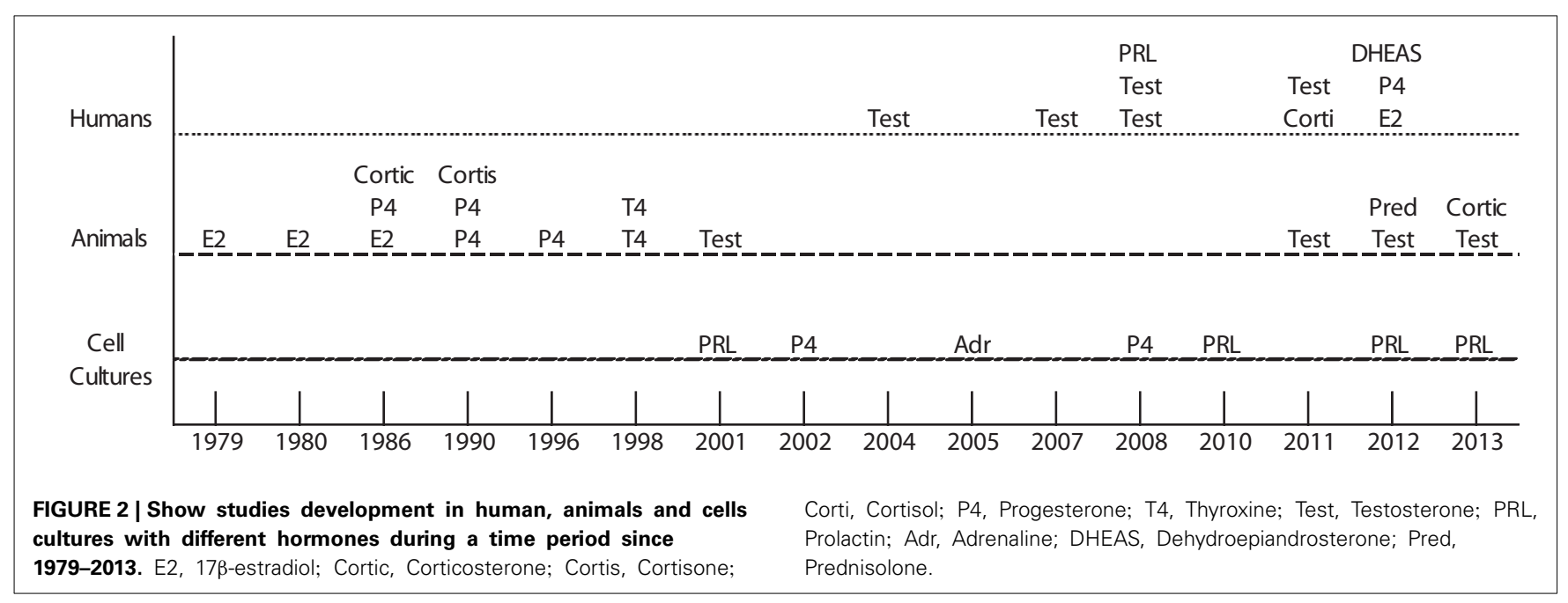

infected women had a higher level, compared to uninfected women.

The study of $17 \beta$-estradiol in $T$. gondii infection began in 1979, when hexoestrol was administered to mice and increased the number of T. gondii cysts in muscle (Kittas and Henry, 1979). At the same time, the susceptibility to T. gondii infection increased in mice when pharmacological estrogen concentrations were used (Pung and Luster, 1986). Nevertheless, 35 years have passed since these experiments were performed and no further studies regarding $17 \beta$-estradiol mechanism in $T$. gondii infection have been reported.

Progesterone levels are reduced during pregnancy in sheep after infection by T. gondii (Aiumalamai et al., 1990; Fredriksson et al., 1990). This hormonal change could be contributing to the susceptibility to T. gondii infection in sheep.

In RAW 264.7 cells infected with tachyzoites of T. gondii, progesterone did not regulate the replication of parasites (GayAndrieu et al., 2002). However, bone marrow stem cells activated with Lippolysaccharide (LPS) and treated with progesterone, while infected with $T$. gondii tachyzoites, cells exhibited a significant reduction in parasite death compared to activated controls (Jones et al., 2008). These results suggest that progesterone can modulate the survival of parasites in vitro.

The results of this study showed that steroid hormones are the most studied toxoplasmosis interaction. However, the information has a great heterogeneity and is not comparable, due to their different experimental designs. For example, the progesterone has been studied in mice (Pung and Luster, 1986), sheep (Aiumalamai et al., 1990), goats (Engeland et al., 1996), and bone marrow stem cells cultures (Jones et al., 2008). Furthermore, in these experiments, different strains and parasite stage of development were used. Moreover, no study has shown how steroid hormones regulate $T$. gondii infection.

The first observation of T. gondii infection and its association with testosterone in humans shows that acute infection by this parasite produced temporary hypogondatrophic gonadal insufficiency (Oktenli et al., 2004). On the other hand, there are several human studies analyzing different genders, using portrait pictures of 89 male students, of which 18 were Toxoplasma infected, and 109 female students. When statistically corrected for age, men with latent toxoplasmosis were perceived as more dominant $(p=0.009)$ and masculine $(p=0.052)$. These results suggest that the higher level of testosterone could be responsible for at least some of the toxoplasmosis-associated shifts in human and animal behavior (Hodková et al., 2007). In 2008, Flegr showed that the relationship between age, gender and 2D:4D ratio in hands sharply increased with Toxoplasma infection. Infected males had higher testosterone levels, while infected females had lower levels, than Toxoplasma-free males and females, respectively. Toxoplasma-infected males had a lower left hand 2D:4D ratio than Toxoplasma-free males. These results suggest that the relationship between $2 \mathrm{D}: 4 \mathrm{D}$ ratio is particularly strong for the left hand and 2D:4D dimorphism will probably be higher in countries with a high prevalence of toxoplasmosis (Flegr et al., 2008b). These results indicate that sexual hormones and gender are key factors determining susceptibility to Toxoplasma infection.

Significantly, lower levels of testosterone in male and female mice with latent toxoplasmosis (strain T38 of $T$. gondii) were compared to uninfected controls (Kaňková et al., 2011). On the other hand, Liesenfeld in 2001 described the effect of sexual steroids and gender in the susceptibility to infection by T. gondii in mice. Death occurred in female mice before males, and mortality in females was associated to an increase in the number of tachyzoites. Female mice testosterone treatment reduced the number of parasites and pathology.

$5 \alpha$-Dihydrotestosterone reduced the number of cysts in mice infected with $T$. gondii cysts strain T45. Mice treated with corticosterone increased twice the number of cysts of T. gondii (Pung and Luster, 1986; Hulínská et al., 1990). These results showed that corticosterone could exacerbate the infection process.

The prevalence of $T$. gondii infection was analyzed in women with hyper and hypoprolactinemia, with a significant increase in this last group (Dzitko et al., 2008). In other studies using peripheral blood mononuclear cells (PBMC) of patients with hyperprolactinemia revealed that exogenous recombinant human prolactin (rhPRL), as well as autologous shPRL from inactivated serum, significantly restricted intracellular growth of Toxoplasma in these cultures (Dzitko et al., 2012). PRL may be one of 
the potential humoral factors implicated in the limitation of T. gondii invasion. A physiological increase in PRL concentration during pregnancy may significantly reduce the risk of $T$. gondii proliferating in the expecting mother (Dzitko et al., 2012).

rhPRL reduced T. gondii replication in human cells (Hs27 y HeLa) and murine cells (L929), (Dzitko et al., 2010, 2013). Afterwards in another experimental study, the replication of parasites was reduced in L929 cells treated with prolactin. These results indicate that the inhibition of replication of $T$. gondii was caused by a limited capacity of the parasites to penetrate host cells, as demonstrated by the reduced number of infected cells. On the other hand, PRL stimulates $\mathrm{T}$ cell proliferation (Clevenger et al., 1992) and the release of various protective cytokines as TNF- $\alpha$ which control efficiently the course of T. gondii infection (Benedetto et al., 2001). The possible PRL action could be bidirectional, namely PRL may limit the proliferation of Toxoplasma via surface host cell receptors (Dzitko et al., 2013) leading to the release of protective type-1 cytokines, such as interleukin 12 (IL-12) and IFN-c (Matalka, 2003), and by inhibiting their penetration ability (Dzitko et al., 2010, 2013).

In the last 35 years, researchers worldwide have made a great effort to advance in the field of knowledge on how the hormones are involved in T. gondii infection, however, a major number of studies and the use of modern molecular methods are required to define the mechanistic role of hormones in the regulation of toxoplasmosis.

\section{IMPLICATIONS FOR RESEARCH}

A crucial factor is the difference in experimental models to study of T. gondii infections and hormones. As well, type's strains and the number limited studies to comparative analysis.

\section{REFERENCES}

Abdoli, A., Dalimi, A., and Movahedin, M. (2012). Impaired reproductive function of male rats infected with Toxoplasma gondii. Andrologia 44, 679-687. doi: 10.1111/j.1439-0272.2011.01249.x

Aiumalamai, S., Fredriksson, G., Uggla, A., Kindahl, H., and Edquist, L. (1990). The effect of Toxoplasrna gondii Infection in Flunixin Meglumine Treated Pregnant Ewes as Monitored by Plasma Levels of 15-Ketodihydroprostaglandin F2a, progeterone, Oestrone Sulphate and Ultrasound Scanning. J. Vet. Med. 37, 23-34. doi: 10.1111/j.1439-0442.1990.tb00872.x

Al-warid, H. S., and Al-qadhi, B. N. (2012). Evaluation of progesterone and estrogen hormonal levels in pregnant women with toxoplasmosis. Eur. J. Sci. Res. 91, 515-519.

Arevalo, M. A., Santos-Galindo, M., Bellini, M. J., Azcoitia, I., and Garcia-Segura, L. M. (2010). Actions of estrogens on glial cells: implications for neuroprotection. Biochim. Biophys. Acta 1800, 1106-1112. doi: 10.1016/j.bbagen.2009.10.002

Benedetto, N., Folgore, A., Romano Carratelli, C., and Galdiero, F. (2001). Effects of cytokines and prolactin on the replication of Toxoplasma gondii in murine microglia. Eur. Cytokine Netw. 12, 348-358.

Cabrera-Muñoz, E., Escobedo, G., Guzmán, C., and Camacho Arroyo, I. (2010). Role of progesterone in HIV and parasitic infections. Open Neuroendocrinol. J. 3, 137-142.

Clevenger, C. V., Sillman, A. L., Hanley-Hyde, J., and Prystowsky, M. B. (1992). Requirement for prolactin during cell cycle regulated gene expression in cloned T-lymphocytes. Endocrinology 130, 3216-3222.

Craig, W. R., Willian, W., and James, A. (2001). Sex-asociated hormones and inmunity to protozoan parasites. Clin. Microbiol. Rev. 14, 476-488. doi: 10.1128/CMR.14.3.476-488.2001

de la Torre, A., Ríos-Cadavid, A. C., Cardozo-García, C. M., Padilla, L., and Gómez-Marín, J. E. (2012). Serum levels of dehydroepiandrosterone sulfate (DHEAS) in ocular toxoplasmosis. J. Microbiol. Immunol. 45, 65-68. doi: 10.1016/j.jmii.2011.09.003
Dionne, P., Robinson, S., and Klein, L. (2012). Pregnancy and pregnancy-associated hormones alter immune responses and disease pathogenesis. Horm. Behav. 62, 263-271. doi: 10.1016/j.yhbeh.2012.02.023

Duenas, M., Torres-Aleman, I., Naftolin, F., and Garcia-Segura, L. M. (1996). Interaction of insulin-like growth factor-I and estradiol signaling pathways on hypothalamic neuronal differentiation. Neuroscience 74, 531-539. doi: 10.1016/0306-4522(96)00142-X

Dzitko, K., Dziadek, B., Gatkowska, J., and Długońska, H. (2013). Toxoplasma gondii binds sheep prolactin. Exp. Parasitol. 134, 216-219. doi: 10.1016/j.exppara.2013.02.010

Dzitko, K., Gatkowska, J., Płociński, P., Dziadek, B., and Długońska, H. (2010). The effect of prolactin (PRL) on the growth of Toxoplasma gondii tachyzoites in vitro. Parasitol. Res. 107, 199-204. doi: 10.1007/s00436-010-1849-3

Dzitko, K., Lawnicka, H., Gatkowska, J., Dziadek, B., Komorowski, J., and Długońska, H. (2012). Inhibitory effect of prolactin on Toxoplasma proliferation in peripheral blood mononuclear cells from patients with hyperprolactinemia. Parasite Immunol. 34, 302-311. doi: 10.1111/j.1365-3024.2012.01359.x

Dzitko, K., Malicki, S., and Komorowski, J. (2008). Effect of hyperprolactinaemia on Toxoplasma gondii prevalence in humans. Parasitol. Res. 102, 723-729. doi: 10.1007/s00436-007-0824-0

el-On, J., and Peiser, J. (2003). Toxoplasma and toxoplasmosis. Harefuah 142, 48-55.

Engeland, I. V., Waldeland, H., Kindahl, H., Ropstad, E., and Andresen, O. (1996). Effect of Toxoplasma gondii infection on the development of pregnancy and on endocrine foetal-placental function in the goat. Vet. Parasitol. 67, 61-74. doi: 10.1016/S0304-4017(96)01025-4

Flegr, J., Lindová, J., and Kodym, P. (2008a). Sex-dependent toxoplasmosisassociated differences in testosterone concentration in humans. Parasitology 135, 427-431. doi: 10.1017/S0031182007004064

Flegr, J., Lindová, J., Pivoñková, V., and Havlícek, J. (2008b). Brief Communication: latent toxoplasmosis and salivary testosterone concentration-important confounding factors in second to fourth digit ratio studies. Am. J. Phys. Anthropol. 137, 479-484. doi: 10.1002/ajpa.20888

Fredriksson, G., Buxton, D., Uggla, A., Kindahl, H., and Edqvist, L. E. (1990). The effect of Toxoplasma gondii infection in unvaccinated and iscom-vaccinated pregnant ewes as monitored by plasma levels of 15-ketodihydroprostaglandin F2 alpha, progesterone, and oestrone sulphate. J. Vet. Med. 37, 113-122. doi: 10.1111/j.1439-0442.1990.tb00882.x

Gardner, D. G., Shoback, D. M., and Greenspan, F. S. (2011). Basic and Clinical Endocrinology. New York, NY: McGraw-Hill Medical.

Gay-Andrieu, F., Cozon, G. J. N., Ferrandiz, J., and Peyron, F. (2002). Progesterone fails to modulate Toxoplasma gondii replication in the RAW 2647 murine macrophage cell line. Parasite Immunol. 24, 173-178. doi: 10.1046/j.13653024.2002.00451.x

Gets, J., and Monroy, F. P. (2005). Effects of alpha- and beta-adrenergic agonists on Toxoplasma gondii infection in murine macrophages. J. Parasitol. 91, 193-195. doi: 10.1645/GE-3242RN

Hodková, H., Kolbeková, P., Skallová, A., Lindová, J., and Flegr, J. (2007). Higher perceived dominance in Toxoplasma infected men-a new evidence for role of increased level of testosterone in toxoplasmosisassociated changes in human behavior. Neuro Endocrinol. Lett. 28, 110-114.

Hulínská, D., Sykora, J., and Zastera, M. (1990). Efect of cortisone on Toxoplasma gondii infection studied by electron microscopy. Folia Parasitol. 37, 207-212.

Jones, L. A., Jean-Paul, A., Henriquez, F. L., Lyons, R. E., Nickdel, M. B., Carter, K. C., et al. (2008). Toll-like receptor-4-mediated macrophage activation is differentially regulated by progesterone via the glucocorticoid and progesterone receptors. Immunol. Lett. 125, 59-69. doi: 10.1111/j.1365-2567.2008.02820.x

Kaňková, S., Kodym, P., and Flegr, J. (2011). Direct evidence of Toxoplasmainduced changes in serum testosterone in mice. Exp. Parasitol. 128, 181-183. doi: 10.1016/j.exppara.2011.03.014

Kittas, C., and Henry, L. (1979). Effect of sex hormones on the immune system of guinea-pigs and on the development of toxoplasmic lesions in non-lymphoid organs. Clin. Exp. Immunol. 36, 16-23.

Kittas, C., and Henry, L. (1980). Effect of sex hormones on the response of mice to infection with Toxoplasma gondii. Br. J. Exp. Pathol. 61, 590-600.

Kurth, F., Luders, E., Sicotte, N. L., Gaser, C., Giesser, B. S., Swerdloff, R. S., et al. (2014). Neuroprotective effects of testosterone treatment in men with multiple sclerosis. Neuroimage Clin. 6, 454-460. doi: 10.1016/j.nicl.2014. 03.001 
Liesenfeld, O., Nguyen, T. A., Pharke, C., and Suzuki, Y. (2001). Importance of gender and sex hormones in regulation of susceptibility of the small intestine to peroral infection with Toxoplasma gondii tissue cysts. J. Parasitol. 87, 1491-1493. doi: 10.1645/0022-3395(2001)087[1491:IOGASH] 2.0.CO;2

Lim, A., Kumar, V., Hari Dass, S. A., and Vyas, A. (2013). Toxoplasma gondii infection enhances testicular steroidogenesis in rats. Mol. Ecol. 22, 102-110. doi: $10.1111 /$ mec. 12042

Matalka, K. Z. (2003). Prolactin enhances production of interferon-gamma, interleukin-12, and interleukin-10, but not of tumor necrosis factor-alpha, in a stimulus-specific manner. Cytokine 21, 187-194. doi: 10.1016/S10434666(02)00496-9

Mitra, R., Sapolsky, R. M., and Vyas, A. (2013). Toxoplasma gondii infection induces dendritic retraction in basolateral amygdala accompanied by reduced corticosterone secretion. Dis. Models Mech. 6, 516-520. doi: 10.1242/dmm. 009928

Montoya, J. G., and Remington, J. S. (2008). Management of Toxoplasma gondii infection during pregnancy. Clin. Infect. Dis. 47, 554-566. doi: 10.1086/590149

O'Shaughnessy, P. J., and Fowler, P. A. (2014). Development of the human fetal testis. Ann. Endocrinol. 75, 48-53. doi: 10.1016/j.ando.2014.03.009

Oktenli, C., Doganci, L., Ozgurtas, T., Araz, R. E., Tanyuksel, M., Musabak, U., et al. (2004). Transient hypogonadotrophic hypogonadism in males with acute toxoplasmosis: suppressive effect of interleukin-1 beta on the secretion of GnRH. Hum. Reprod. 19, 859-866. doi: 10.1093/humrep/ deh161

Ortiz-Alegría, L. B., Caballero-Ortega, H., Cañedo-Solares, I., Rico-Torres, C. P., Sahagún-Ruiz, A., Medina-Escutia, M. E., et al. (2010). Congenital toxoplasmosis: candidate host immune genes relevant for vertical transmission and pathogenesis. Genes Immun. 11, 363-373. doi: 10.1038/gene.2010.21

Pfaff, A. W., Mousli, M., Sénégas, A., Marcellin, L., Takikawa, O., Klein, J. P., et al. (2008). Impact of foetus and mother on IFN-gamma-induced indoleamine 2,3-dioxygenase and inducible nitric oxide synthase expression in murine placenta following Toxoplasma gondii infection. Int. J. Parasitol. 38, 249-258. doi: 10.1016/j.ijpara.2007.07.007

Prigione, I., Chiesa, S., Taverna, P., Ceccarelli, R., Frulio, R., Morandi, F., et al. (2006). T cell mediated immune responses to Toxoplasma gondii in pregnant women with primary toxoplasmosis. Microbes Infect. 8, 552-560. doi: 10.1016/j.micinf.2005.08.008

Pung, O. J., and Luster, M. I. (1986). Toxoplasma gondii: decreased resistance to infection in mice due to estrogen. Exp. Parasitol. 61, 48-56. doi: 10.1016/00144894(86)90134-7

Puvanesuaran, V. R., Nowroji, K., Sreenivasan, S., Noordin, R., and Balakrishnan, V. (2012). Use of prednisolone to aid propagation of Toxoplasma gondii in mice. Eur. Rev. Med. Pharmacol. Sci. 16, 1028-1032.
Roberts, C. W., Walker, W., and Alexander, J. (2001). Sex-associated hormones and immunity to protozoan parasites. Clin. Microbiol. Rev. 14, 476-488. doi: 10.1128/CMR.14.3.476-488.2001

Senegas, A., Villard, O., Neuville, A., Marcellin, L., Pfaff, A. W., Steinmetz, T., et al. (2009). Toxoplasma gondii-induced foetal resorption in mice involves interferon-gamma-induced apoptosis and spiral artery dilation at the maternofoetal interface. Int. J. Parasitol. 39, 481-487. doi: 10.1016/j.ijpara.2008.08.009

Shirbazou, S., Abasian, L., and Talebi, M. F. (2011). Effects of Toxoplasma gondii infection on plasma testosterone and cortisol level and stress index on patients referred to Sina hospital, Tehran. Jundishapur J. Microbiol. 4, 167-173.

Speroff, L., Glass, R. H., and Kase, N. G. (1999). Clinical Ginecologic Endocrinology and Infertility, 6th Edn. Philadelphia, PA: Lippincott Willians \&Wilkins.

Stahl, W., Dias, J. A., and Turek, G. (1985). Hypothalamic-adenohypophyseal origin of reproductive failure in mice following chronic infection with Toxoplasma gondii. Proc. Soc. Exp. Biol. Med. 178, 246-249. doi: 10.3181/00379727-17842006

Stahl, W., and Kaneda, Y. (1998a). Impaired thyroid function in murine toxoplasmosis. Parasitology 117(Pt 3), 217-222. doi: 10.1017/S003118209800300X

Stahl, W., and Kaneda, Y. (1998b). Aetiology of thyroidal dysfunction in murine toxoplasmosis. Parasitology 117(Pt 3), 223-227. doi: 10.1017/S0031182098003035

Stahl, W., Kaneda, Y., and Noguchi, T. (1994). Reproductive failure in mice chronically infected with Toxoplasma gondii. Parasitol. Res. 80, 22-28. doi: 10.1007/BF00932619

Conflict of Interest Statement: The authors declare that the research was conducted in the absence of any commercial or financial relationships that could be construed as a potential conflict of interest.

Received: 10 April 2014; accepted: 08 September 2014; published online: 09 October 2014.

Citation: Galván-Ramírez ML, Gutiérrez-Maldonado AF, Verduzco-Grijalva F and Jiménez JMD (2014) The role of hormones on Toxoplasma gondii infection: a systematic review. Front. Microbiol. 5:503. doi: 10.3389/fmicb.2014.00503

This article was submitted to Microbial Immunology, a section of the journal Frontiers in Microbiology.

Copyright (c) 2014 Galván-Ramírez, Gutiérrez-Maldonado, Verduzco-Grijalva and Jiménez. This is an open-access article distributed under the terms of the Creative Commons Attribution License (CC BY). The use, distribution or reproduction in other forums is permitted, provided the original author(s) or licensor are credited and that the original publication in this journal is cited, in accordance with accepted academic practice. No use, distribution or reproduction is permitted which does not comply with these terms. 